BMJ Open Diabetes Research \& Care

\section{Diabetes care and outcomes for American Indians and Alaska natives in commercial integrated delivery systems: a SUrveillance, PREvention, and ManagEment of Diabetes Mellitus (SUPREME-DM) Study}

To cite: Schmittdiel JA, Steiner JF, Adams AS, et al. Diabetes care and outcomes for American Indians and Alaska natives in commercial integrated delivery systems: a SUrveillance, PREvention, and ManagEment of Diabetes Mellitus (SUPREME-DM) Study. BMJ Open Diabetes Research and Care 2014;2: e000043. doi:10.1136/ bmjdrc-2014-000043

Prior Presentations: The material in this manuscript has not presented at any meetings.

Received 14 July 2014 Revised 23 September 2014 Accepted 14 October 2014

CrossMark

For numbered affiliations see end of article.

Correspondence to Julie Schmittdiel; Julie.A.Schmittdiel@kp.org

\section{ABSTRACT}

Objective: To compare cardiovascular disease risk factor testing rates and intermediate outcomes of care between American Indian/Alaska Native (AI/AN) patients with diabetes and non-Hispanic Caucasians enrolled in nine commercial integrated delivery systems in the USA. Research design and methods: We used modified Poisson regression models to compare the annual testing rates and risk factor control levels for glycated haemoglobin (HbA1c), low-density lipoprotein cholesterol (LDL-C), and systolic blood pressure (SBP); number of unique diabetes drug classes; insulin use; and oral diabetes drug medication adherence between insured $\mathrm{Al} / \mathrm{AN}$ and non-Hispanic white adults with diabetes aged $\geq 18$ in 2011.

Results: $5831 \mathrm{Al} / \mathrm{AN}$ patients ( $1.8 \%$ of the cohort) met inclusion criteria. After adjusting for age, gender, comorbidities, insulin use, and geocoded socioeconomic status, Al/AN patients had similar rates of annual $\mathrm{HbA1C}$, LDL-C, and SBP testing, and LDL-C and SBP control, compared with non-Hispanic Caucasians. However, Al/AN patients were significantly more likely to have $\mathrm{HbA} 1 \mathrm{c}>9 \%$ (>74.9 mmol/mol; $\mathrm{RR}=1.47,95 \% \mathrm{Cl} 1.38$ to 1.58 ), and significantly less likely to adhere to their oral diabetes medications ( $R R=0.90,95 \% \mathrm{Cl} 0.88$ to 0.93 ) compared with nonHispanic Caucasians.

Conclusions: AI/AN patients in commercial integrated delivery systems have similar blood pressure and cholesterol testing and control, but significantly lower rates of $\mathrm{HbA} 1 \mathrm{C}$ control and diabetes medication adherence, compared with non-Hispanic Caucasians. As more Al/ANs move to urban and suburban settings, clinicians and health plans should focus on addressing disparities in diabetes care and outcomes in this population.

American Indians and Alaska Natives (AI/AN) are more than twice as likely to

\section{Key messages}

In a large cohort of over $\mathbf{3 0 0} \mathbf{0 0 0}$ patients within nine US commercial integrated delivery systems

- American Indian/Alaska Native (AI/AN) patients were significantly more likely to have poor glycated haemoglobin $(\mathrm{HbA} 1 \mathrm{c})$ control compared with non-Hispanic Caucasians.

- Al/AN patients were significantly less likely to adhere to their oral diabetes medications.

- Al/AN patients had similar rates of annual $\mathrm{HbA1c}$, low-density lipoprotein cholesterol (LDL-C), and systolic blood pressure testing, and LDL-C and systolic blood pressure control compared with non-Hispanic Caucasians.

\section{Emerging research questions}

- How can we improve diabetes care and outcomes of care for Al/AN patients receiving care outside the Indian Health Service?

- What are the best ways to address disparities in care for Al/AN patients with diabetes in urban and suburban healthcare settings?

- What are the healthcare system-level predictors of high-quality diabetes care for AI/AN patients?

have diabetes as non-Hispanic Caucasians ${ }^{1}$; the prevalence of diabetes in $\mathrm{AI} / \mathrm{AN}$ populations has increased by more than $68 \%$ since $1994 .^{2}$ In addition, up to $30 \%$ of $\mathrm{AI} / \mathrm{AN}$ have prediabetes, ${ }^{2}$ or higher-than-normal blood sugar levels associated with increased risk of type 2 diabetes. There are significant disparities in diabetes outcomes for $\mathrm{AI} / \mathrm{AN}$ patients: for example, the death rate from diabetes in $\mathrm{AI} / \mathrm{AN}$ patients is 1.6 times higher than in the general population. ${ }^{3}$ Cardiovascular disease (CVD), which is strongly associated with diabetes, also is 
increasingly common in the AI/AN population. ${ }^{45}$ The costs of caring for diabetes and its complications are high; a recent study revealed that in one of the Indian Health Services' (IHS) major facilities, $10.9 \%$ of its patients with diabetes consumed nearly $38 \%$ of the total dollars available to meet the health needs of its entire user population. ${ }^{6}$

Most studies of the care and outcomes for $\mathrm{AI} / \mathrm{AN}$ patients with diabetes, including CVD risk factor monitoring and levels of control, have been conducted within the IHS. The IHS, a part of the US Department of Health and Human Services, provides health services to approximately 1.9 million AI/AN members of more than 500 federally recognized tribes, and is the primary federal healthcare provider for Indian people. ${ }^{7}$ The IHS provides a level of diabetes guideline-concordant care that is comparable to other race/ethnicity groups in general healthcare settings. ${ }^{8}$

However, little is known regarding the quality of diabetes care for $\mathrm{AI} / \mathrm{AN}$ patients seen in other clinical settings. This is especially true with respect to the $60 \%$ of $\mathrm{AI} / \mathrm{ANs}$ who live in non-tribal metropolitan areas. ${ }^{10}$ A major exception is a recent report released by the Urban Indian Health Institute that describes trends in diabetes care and clinical outcomes for $3603 \mathrm{AI} / \mathrm{AN}$ patients served between 2008 and 2012 by 30 urban Indian health organizations. ${ }^{11}$ Using IHS Diabetes Audit data, the report observed a $5 \%$ increase over the 5 -year period in the percentage of participants with diabetes whose mean blood pressure fell within the range of $<130$ systolic/ $<80$ diastolic. Similarly, mean low-density lipoprotein cholesterol (LDL-C) decreased 3\% over the same timeframe. Unfortunately, these analyses were limited by substantial missing data for select variables, by limited demographic information, by the inability to track individual patients over time, and by the lack of key measures such as medication adherence and other comorbidities.

The purpose of this study is to determine the demographic and clinical characteristics, including rates of CVD risk factor (HbA1c, LDL-C, and systolic blood pressure (SBP)) testing, control, and oral diabetic medication adherence, of AI/ANs with diabetes receiving care from a national research network of commercial integrated delivery systems, and to compare them to their non-Hispanic white counterparts within the same systems.

\section{RESEARCH DESIGN AND METHODS}

\section{Study setting and population}

The study cohort was drawn from the membership of The SUrveillance PREvention and ManagEment of Diabetes Mellitus (SUPREME-DM) study health systems between 1 January 2011 and 31 December 2011. SUPREME-DM combines patient demographic, healthcare utilization, diagnosis, procedure, medication, and laboratory data from EHR and other clinical and administrative databases of 11 integrated US healthcare systems. Because the SUPREME-DM distributed database (known as the DataLink) represents a defined population with over one million patients with diabetes, it provides an exceptionally robust, geographic, and race/ethnicity-distributed research resource. ${ }^{12}$ The nine SUPREME-DM sites participating in the current study include: HealthPartners (Minnesota), Group Health (Washington), Marshfield Clinic (Wisconsin), and Kaiser Permanente regions in Colorado (KPCO), Northern California (KPNC), Southern California (KPSC), Hawaii (KPHI), Georgia (KPGA), and the Northwest (KPNW). Members in these health plans receive their insurance through commercial group and self-paid plans, and Medicare and Medicaid.

For the current study, patients with diabetes were identified using the SUPREME-DM DataLink, and were included if they were age 18 or older as of 1 January 2011, and had self-identified race/ethnicity as either $\mathrm{AI} / \mathrm{AN}$ (either as a primary or secondary racial category), or non-Hispanic Caucasian (as their primary racial category). ${ }^{13}$ Presence of diabetes was established by: at least one inpatient or two outpatient diagnoses of diabetes (ICD-9-CM 250.xx, 357.2, 366.41, 362.01$362.07)$ on separate dates no more than 2 years apart; or fasting plasma glucose $\geq 126 \mathrm{mg} / \mathrm{dL}$, random plasma glucose $\geq 200 \mathrm{mg} / \mathrm{dL}, \mathrm{HbAlc} \geq 6.5 \%(\mathrm{mmol} / \mathrm{mol} \geq 47.5)$; at least two abnormal ambulatory tests were required. Patients with more than a 90-day gap in membership with their health plan in 2011 were excluded.

For the eligible cohort, we used the DataLink to obtain patient demographics, geocoded Census-block group level education and income, and presence of key comorbidities (eg, hypertension, hyperlipidemia, depression, chronic kidney disease, obesity) using the Quan Modified Elixhauser comorbidity index ${ }^{14}$ based on ICD-9 codes in the 12 months following the date of diabetes determination. The Quan Modified Elixhauser index is a comprehensive, widely used measure of comorbidity that has been consistently shown to be correlated with healthcare outcomes. ${ }^{15}$

We used the DataLink to determine whether HbA1c and LDL-C tests were performed in 2011 for each patient, and to determine the results of those tests. SBP levels for 2011 were determined using measurements from outpatient visits (excluding those from urgent care and emergency department visits). Our analyses focused on HbAlc, blood pressure, and cholesterol testing and control for patients with diabetes, since these 'ABCs' for controlling CVD risk are widely considered to be the critical elements for reducing CVD-related mortality and morbidity. ${ }^{16}$ Risk factor control was calculated based on last measurement in 2011 using cut-off points of HbA1c $>9 \%(>74.9 \mathrm{mmol} / \mathrm{mol})$, LDL-C $\geq 100 \mathrm{mg} / \mathrm{dL}$, and SBP $\geq 130 \mathrm{~mm} \mathrm{Hg}$.

We calculated the number of oral diabetes drug classes dispensed, and whether insulin was dispensed, in 2011 using DataLink pharmacy data. To assess adherence to oral diabetes medications, we used pharmacy refill data to determine the cumulative period for which medication was available to the patient, dividing the 
number of days for which the patient had the medication by the number of days in the study window for that participant. Adherence ranges from 100\% (completely adherent) to $0 \%$ (completely non-adherent). We then dichotomized the adherence values, considering $\geq 80 \%$ as a marker of good adherence. ${ }^{17-19}$ This adherence threshold has been used in previous studies that examined the relationship between medication adherence and both hospitalizations and mortality rates. ${ }^{20-22}$ If a patient was taking more than one antidiabetic medication during 2011, the adherence for each medication was combined into a weighted average based on the number of days the patient had days' supply for each prescription. We restricted our analysis of drug use and medication adherence to the $87 \%$ of patients with prescription drug coverage in their health plan in 2011.

\section{Statistical analysis}

To compare the CVD risk factor testing, control, and oral diabetes medication adherence between the AI/AN and non-Hispanic white population, we performed seven separate modified Poisson regression models ${ }^{23}$ using HbA1c $>9 \%$, having no HbA1c test in 2011, LDL-C $\geq 100$, having no LDL-C laboratory test in 2011, SBP $\geq 130$, having no SBP reading in 2011, and oral diabetes medication adherence $\geq 80 \%$ as the respective dichotomous dependent variables, and race/ethnicity as the main independent variable. Modified Poisson regressions directly estimate risk ratios when outcomes are common. ${ }^{23-25}$ These models adjusted for age, gender, Quan Modified Elixhauser comorbidity score, duration of diabetes, delivery system site, and geocoded socioeconomic status; the models for HbA1c control and diabetes medication adherence also adjusted for insulin use as a marker for disease severity. ${ }^{26}$

All data analyses were performed with SAS V.9.3. This study was approved by the KPCO Institutional Review Board (IRB) and each participating site either ceded oversight to the KPCO IRB or received approval from their local site IRB.

\section{RESULTS}

We identified 328908 patients in 2011 who selfidentified as either AI/AN ( $\mathrm{n}=5831)$ or non-Hispanic Caucasian ( $\mathrm{n}=323077$; table 1 ). AI/AN patients were younger (59 vs 64 years, $\mathrm{p}<0.0001$ ), more likely to be female ( $52 \%$ vs $47 \%, \mathrm{p}<0.0001)$, had a lower Quan comorbidity score $(2.74$ vs $2.86, \mathrm{p}<0.0001)$, and resided in geocoded Census block groups with lower income and education levels $(p<0.0001)$.

After adjusting for age, gender, comorbidities, duration of diabetes, insulin use, and geocoded socioeconomic status (table 2), AI/AN patients were significantly more likely to have HbA1c $>9 \% \quad(R R=1.41$, $95 \%$ CI 1.31 to 1.51$)$ compared with non-Hispanic Caucasians. AI/AN patients were also significantly less likely to be adherent to their oral diabetes medications
( $R R=0.90,95 \%$ CI 0.88 to 0.93$)$. AI/AN patients had similar rates of HbAlc, LDL-C, and SBP testing, as well as similar rates of LDL-C and SBP control, compared with non-Hispanic Caucasians. Sensitivity analyses examining the adjusted differences in continuous measures of HbA1c, LDL-C, and SBP in 2011 also showed significantly higher HbAlc levels in $\mathrm{AI} / \mathrm{AN}$ patients, and no differences in LDL-C and SPB levels, compared with non-Hispanic Caucasians (data not shown). Additional sensitivity analyses including only $\mathrm{AI} / \mathrm{AN}$ patients who selected $\mathrm{AI} / \mathrm{AN}$ as their primary racial category in the DataLink, and including drug coverage as a covariate, also showed similar results (data not shown).

\section{DISCUSSION}

To the best of our knowledge, this study is the first to examine diabetes care and outcomes in a large, nationally based sample of AI/AN patients receiving care from integrated, commercial delivery systems outside the IHS and its urban affiliates. We found that AI/AN patients were younger, more likely to be female, had fewer comorbidities, and lived in Census block groups with lower socioeconomic status compared with the non-Hispanic Caucasians with diabetes in the same delivery systems. After adjusting for these demographic, socioeconomic, and clinical differences, testing rates and outcomes of care for blood pressure and lipids were similar in both groups. Since the risk for CVD in AI/AN adults with diabetes is up to eight times higher than in the $\mathrm{AI} / \mathrm{AN}$ population without diabetes, ${ }^{27}$ it is encouraging that no disparities were evident in the management of these CVD risk factors in $\mathrm{AI} / \mathrm{AN}$ patients within these delivery systems.

However, we found that AI/AN patients with diabetes had lower rates of HbAlc control, and lower rates of medication adherence to diabetes-related medications, than non-Hispanic white patients with diabetes. Previous studies have found disparities between non-Hispanic Caucasians and other racial/ethnic groups in the use of prescription medications in patients with diabetes, ${ }^{28-29}$ and in HbAlc control. ${ }^{30-31}$ While some have suggested that disparities can be ameliorated when healthcare is delivered in a less fragmented, more integrated system of care, ${ }^{32-33}$ other studies indicate that disparities in medication use, adherence, and outcomes may persist even within integrated systems. ${ }^{34-36}$ By using a large, nationally based sample of AI/AN patients with diabetes in non-IHS healthcare settings, this is the first study to document that such disparities may exist in $\mathrm{AI} / \mathrm{AN}$ patients receiving care in commercial integrated delivery systems.

Previous studies have suggested that healthcare systemlevel interventions have the potential to ameliorate racial/ethnic disparities in diabetes medication adherence and outcomes in patients with diabetes. ${ }^{36-38}$ As a larger share of the $\mathrm{AI} / \mathrm{AN}$ population moves to metropolitan areas and receives medical care from commercial health plans, health systems should consider ways to 


\begin{tabular}{|c|c|c|c|}
\hline Variable & $\begin{array}{l}\text { Overall } \\
(n=328908)\end{array}$ & $\begin{array}{l}\text { Non-Hispanic Caucasian } \\
(\mathrm{n}=323077)\end{array}$ & $\begin{array}{l}\text { American Indian, Alaska } \\
\text { Native }(n=5831)\end{array}$ \\
\hline Age on 1 January 2011, mean (SD) & $64(13)$ & $64(13)$ & $59(13)^{\star \star \star}$ \\
\hline Female $(\%)$ & 47 & 47 & $52^{* \star *}$ \\
\hline $\begin{array}{l}\text { Census block group: per cent of households with } \\
\text { below-poverty level income (\%) }\end{array}$ & 8 & 8 & $10^{\star * \star}$ \\
\hline $\begin{array}{l}\text { Census block group: per cent of pop age } 25+ \\
\text { with high school education at most (\%) }\end{array}$ & 39 & 38 & $45^{\star \star \star}$ \\
\hline \multicolumn{4}{|l|}{ Type of insurance in year 2011 (\%) } \\
\hline Commercial & 76 & 76 & $80^{\star \star \star}$ \\
\hline Medicaid & 2 & 2 & $4^{\star \star \star}$ \\
\hline Medicare & 17 & 17 & $11^{\star \star \star}$ \\
\hline Unknown & 5 & 5 & 5 \\
\hline Duration of diabetes (in years), mean (SD) & $6.86(3.92)$ & $6.87(3.92)$ & $6.74(3.99)^{*}$ \\
\hline Quan Modified Elixhauser Comorbidity & $2.86(1.99)$ & $2.86(2.00)$ & $2.74(1.91)^{\star \star \star}$ \\
\hline \multicolumn{4}{|l|}{ Scale mean (SD) } \\
\hline Depression (\%) & 14 & 14 & 14 \\
\hline CKD (\%) & 5 & 5 & $4^{\star \star \star}$ \\
\hline Hypertension (\%) & 58 & 58 & $51^{\star \star *}$ \\
\hline \multicolumn{4}{|l|}{ CVD risk factors in year 2011} \\
\hline HbA1c, mean (SD) & $7.2(1.4)$ & $7.2(1.4)$ & $7.7(1.7)^{\star \star \star}$ \\
\hline $\mathrm{HbA} 1 \mathrm{c}>9(\%)$ & 9 & 9 & $15^{\star \star *}$ \\
\hline$\%$ no HbA1c laboratory test & 12 & 12 & 13 \\
\hline Number of $\mathrm{HbA} 1 \mathrm{c}$ laboratory tests, mean (SD) & $1.82(1.22)$ & $1.82(1.22)$ & $1.83(1.23)$ \\
\hline LDL, mean (SD) & $88(31)$ & $88(31)$ & $91(32)^{\star \star \star}$ \\
\hline LDL <100 (\%) & 73 & 74 & $70^{* \star *}$ \\
\hline$\%$ no LDL laboratory test & 11 & 11 & $14^{\star \star \star}$ \\
\hline Number of LDL laboratory tests, mean (SD) & $1.52(1.04)$ & $1.52(1.04)$ & $1.44(1.01)^{\star \star \star}$ \\
\hline $\mathrm{SBP}$, mean (SD) & $127(12)$ & $127(12)$ & $127(12)$ \\
\hline $\mathrm{SBP}<130(\%)$ & 58 & 58 & 58 \\
\hline$\%$ no SBP measurement & 5.6 & 5.6 & $6.2^{*}$ \\
\hline Number of SBP measurements, mean (SD) & $5.80(6.09)$ & $5.80(6.09)$ & $5.79(6.01)$ \\
\hline Had fill of an oral diabetes drug in $2011 \dagger(\%)$ & 57 & 57 & $62^{* \star *}$ \\
\hline Had insulin fill in $2011 \dagger(\%)$ & 24 & 24 & $26^{\star \star \star}$ \\
\hline Diabetes drug classes dispensed, mean (SD)† & $1.25(1.11)$ & $1.24(1.11)$ & $1.35(1.10)^{\star \star \star}$ \\
\hline Diabetes drug adherence is $\geq 80 \%(\%) \ddagger$ & 77 & 78 & $68^{\star \star *}$ \\
\hline
\end{tabular}

${ }^{*}$ Statistically significant at $p<0.05 ;{ }^{* *} p<0.01 ;{ }^{* *} p<0.001$.

†Restricted to patients with drug coverage in year 2011 ( $n=285050)$.

†Restricted to patients who had two or more fills of an oral diabetes medication in the same drug class in year 2011, and who had drug coverage in year $2011(n=151210)$.

CKD, chronic kidney disease; CVD, cardiovascular disease; HbA1c, glycated haemoglobin; LDL, low-density lipoprotein; SBP, systolic blood pressure.

identify system-level barriers and facilitators to medication adherence and HbAlc control in their $\mathrm{AI} / \mathrm{AN}$ patients with diabetes. These efforts have the potential to address the increased risk of diabetes and CVD risk within $\mathrm{AI} / \mathrm{ANs}$.

Limitations to this study include the inability to distinguish between type 1 and type 2 diabetes within the SUPREME-DM population, the potential misclassification of race based on our administrative data, and the potential misclassification of comorbidities based on ICD-9 data alone. In addition, while the SUPREME-DM DataLink includes geocoded data on income and education, it does not have individual patient-level socioeconomic status data; both socioeconomic and cultural factors may contribute to differences in AI/AN population diabetes outcomes compared with those of other racial/ethnic groups. Risk factor control was determined using the last value in the measurement year; while this is consistent with Healthcare Effectiveness Data and Information Set (HEDIS) and other national quality metrics, using one measure may not adequately reflect the variability of these measures. The findings of a study of the insured population in the SUPREME-DM systems may not generalize to the diabetes population in all healthcare systems or to the uninsured, although members of these health plans are diverse and receive their insurance through Medicare and Medicaid as well as through commercial plans. However, as these integrated healthcare systems exemplify care models recommended by recent legislation such as meaningful use of EHR data, primary care medical homes, and integrated care, ${ }^{39-41}$ our results provide a critical and timely 


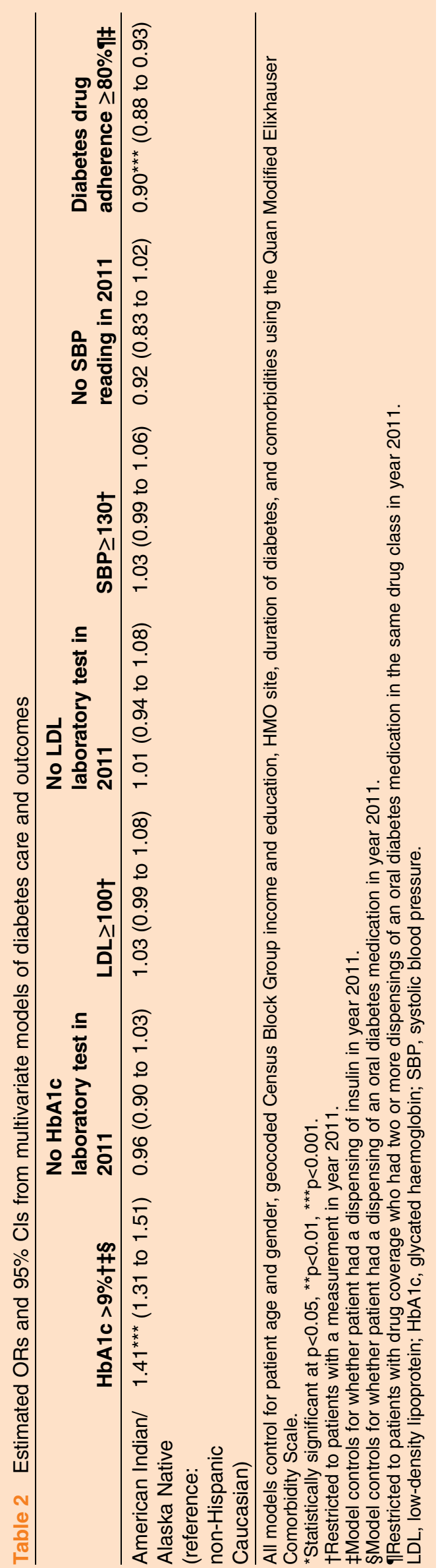

benchmark for the quality of care for AI/AN patients receiving healthcare outside the IHS.

\section{CONCLUSIONS}

$\mathrm{AI} / \mathrm{AN}$ patients with diabetes in commercial integrated delivery systems have similar blood pressure and cholesterol outcomes, but significantly lower rates of HbAlc control and diabetes medication adherence, compared with non-Hispanic Caucasians. Given that more than half of AI/ANs live and work in urban and suburban settings, clinicians and health plans should focus on health system-level efforts to address disparities in diabetes care and outcomes in this population.

Author affiliations

${ }^{1}$ Division of Research, Kaiser Permanente Northern California, Oakland, California, USA

${ }^{2}$ Institute for Health Research, Kaiser Permanente Colorado, Denver, Colorado, USA

${ }^{3}$ Centers for American Indian and Alaska Native Health, Colorado School of Public Health, University of Colorado Denver, Denver, Colorado, USA ${ }^{4}$ HealthPartners Institute for Education and Research, Minneapolis, Minnesota, USA

${ }^{5}$ Group Health Research Institute, Seattle, Washington, USA

${ }^{6}$ Kaiser Permanente Center for Health Research, Portland, Oregon, USA

${ }^{7}$ Department of Research \& Evaluation, Kaiser Permanente Southern California, Pasadena, California, USA

${ }^{8}$ Kaiser Permanente Hawaii, Honolulu, Hawaii, USA

${ }^{9}$ Kaiser Permanente Georgia Center for Health Research-Southeast, Atlanta, Georgia, USA

${ }^{10}$ Marshfield Clinic

Contributors JAS wrote the manuscript and researched the data. JFS, ASA, JB, WGH, RFH and SMM researched the data, contributed to the discussion, and reviewed/edited the manuscript. WD analyzed the data and reviewed/ edited the manuscript. JD, LSM, GAN, JML, BW, MGB, and RDP provided access to study data, and reviewed/edited the manuscript. JAS serves as the guarantor of this manuscript.

Funding This work was supported by grant number R01HS019859 from the Agency for Healthcare Research and Quality, and by The Center for American Indian and Alaska Native Diabetes Translational Research (CAIANDTR; P30DK092923). The content is solely the responsibility of the authors and does not necessarily represent the official views of the Agency for Healthcare Research and Quality. JAS and ASA received additional support from the NIDDK-funded Health Delivery Systems Center for Diabetes Translational Research (1P30 DK92924).

Competing interests None.

Ethics approval Kaiser Permanente IRB.

Provenance and peer review Not commissioned; externally peer reviewed.

Data sharing statement Data sets for this study were created in a manner that is consistent with human subject protections and HIPAA privacy regulations. Source data were kept behind institutions' firewalls by each of the participating sites. Local sites have created data dictionaries, coding manuals, and other documentation relevant to data collection and measurement issues; these resources can be publicly shared on request. Individual health plans are the stewards of source data, which will not be publicly shared.

Open Access This is an Open Access article distributed in accordance with the Creative Commons Attribution Non Commercial (CC BY-NC 4.0) license, which permits others to distribute, remix, adapt, build upon this work noncommercially, and license their derivative works on different terms, provided the original work is properly cited and the use is non-commercial. See: http:// creativecommons.org/licenses/by-nc/4.0/ 


\section{REFERENCES}

1. Centers for Disease Control. National Diabetes Fact Sheet, 2011. http://www.cdc.gov/diabetes/pubs/pdf/ndfs_2011.pdf (accessed 22 July 2013).

2. American Diabetes Association. Native American Complications. http://www.diabetes.org/living-with-diabetes/treatment-and-care/ high-risk-populations/treatment-american-indians.html (accessed 1 July 2013).

3. U.S. Department of Health and Human Services. Diabetes in American Indians and Alaskan Natives Facts at a Glance. http:// www.ihs.gov/MedicalPrograms/Diabetes/HomeDocs/Resources/ FactSheets/2012/Fact_sheet_AIAN_508c.pdf (accessed 2 July 2013).

4. Howard BV, Lee ET, Cowan LD, et al. Rising tide of cardiovascular disease in American Indians. The Strong Heart Study. Circulation 1999;99:2389-95.

5. Jolly S, Kao C, Bindman AB, et al. Cardiac procedures among American Indians and Alaska Natives compared to non-Hispanic whites hospitalized with ischemic heart disease in California. J Gen Intern Med 2010;25:430-4.

6. O'Connell JM, Wilson C, Manson SM, et al. The costs of treating American Indian adults with diabetes within the Indian Health Service. Am J Public Health 2012;102:301-8.

7. U.S. Department of Health and Human Services. Indian Health Service. The Federal Health Program for American Indians and Alaska Natives. http://www.ihs.gov/aboutihs/ (accessed 5 March 2014).

8. Acton KJ, Shields R, Rith-Najarian S, et al. Applying the diabetes quality improvement project indicators in the Indian Health Service primary care setting. Diabetes Care 2001;24:22-6.

9. Saaddine JB, Engelgau MM, Beckles GL, et al. A diabetes report card for the United States: quality of care in the 1990s. Ann Intern Med 2002;136:565-74.

10. U.S. Department of Health and Human Services. American Indian and Alaska Native Profile. http://minorityhealth.hhs.gov/templates/ browse. aspx?|v|=2\&|v|ID=52 (accessed 5 March 2014).

11. Urban Diabetes Care and Outcomes Summary Report: Aggregate Results from Urban Indian Health Organizations. Urban Indian Health Institute: A Division of the Seattle Indian Health Board, 2013.

12. Nichols GA, Desai J, Elston Lafata J, et al. Construction of a multisite DataLink using electronic health records for the identification, surveillance, prevention, and management of diabetes mellitus: the SUPREME-DM project. Prev Chronic Dis 2012;9:E110.

13. Ulmer C, McFadden B, Nerenz DR; Institute of Medicine (U.S.). Subcommittee on Standardized Collection of Race/Ethnicity Data for Healthcare Quality Improvement Board on Health Care Services. Race, ethnicity, and language data: standardization for health care quality improvement. Washington DC: National Academies Press, 2009.

14. van Walraven $C$, Austin $P C$, Jennings $A$, et al. A modification of the Elixhauser comorbidity measures into a point system for hospital death using administrative data. Med Care 2009;47:626-33.

15. Li B, Evans D, Faris $P$, et al. Risk adjustment performance of Charlson and Elixhauser comorbidities in ICD-9 and ICD-10 administrative databases. BMC Health Serv Res 2008;8:12.

16. Stark Casagrande S, Fradkin JE, Saydah $\mathrm{SH}$, et al. The prevalence of meeting A1c, blood pressure, and LDL goals among people with diabetes 1988-2010. Diabetes Care 2013;36:2271-9.

17. Steiner JF, Koepsell TD, Fihn SD, et al. A general method of compliance assessment using centralized pharmacy records. Description and validation. Med Care 1988;26:814-23.

18. Steiner JF, Prochazka AV. The assessment of refill compliance using pharmacy records: methods, validity, and applications. J Clin Epidemiol 1997;50:105-16

19. Grymonpre $\mathrm{R}$, Cheang $\mathrm{M}$, Fraser $\mathrm{M}$, et al. Validity of a prescription claims database to estimate medication adherence in older persons. Med Care 2006;44:471-7.
20. Ho PM, Rumsfeld JS, Masoudi FA, et al. Effect of medication nonadherence on hospitalization and mortality among patients with diabetes mellitus. Arch Intern Med 2006;166:1836-41.

21. Lau DT, Nau DP. Oral antihyperglycemic medication nonadherence and subsequent hospitalization among individuals with type 2 diabetes. Diabetes Care 2004;27:2149-53.

22. Sokol MC, McGuigan KA, Verbrugge RR, et al. Impact of medication adherence on hospitalization risk and healthcare cost. Med Care 2005;43:521-30.

23. Zou G. A modified poisson regression approach to prospective studies with binary data. Am J Epidemiol 2004;159:702-6.

24. Kind AJ, Bartels C, Mell MW, et al. For-profit hospital status and rehospitalizations at different hospitals: an analysis of Medicare data. Ann Intern Med 2010;153:718-27.

25. Knol MJ, Le Cessie S, Algra A, et al. Overestimation of risk ratios by odds ratios in trials and cohort studies: alternatives to logistic regression. CMAJ 2012;184:895-9.

26. Boyne MS, Saudek CD. Effect of insulin therapy on macrovascular risk factors in type 2 diabetes. Diabetes Care 1999;22(Suppl 3): C45-53.

27. Bloomgarden ZT. Approaches to cardiovascular disease and its treatment. Diabetes Care 2003;26:3342-8.

28. Briesacher B, Limcangco R, Gaskin D. Racial and ethnic disparities in prescription coverage and medication use. Health Care Financ Rev 2003;25:63-76.

29. Stuart B, Yin X, Davidoff A, et al. Impact of part D low-income subsidies on medication patterns for Medicare beneficiaries with diabetes. Med Care 2012;50:913-19.

30. Kirk JK, D'Agostino RB Jr, Bell RA, et al. Disparities in HbA1c levels between African-American and non-Hispanic white adults with diabetes: a meta-analysis. Diabetes Care 2006;29:2130-6.

31. Kirk JK, Passmore LV, Bell RA, et al. Disparities in A1C levels between Hispanic and non-Hispanic white adults with diabetes: a meta-analysis. Diabetes Care 2008;31:240-6.

32. Smedley BD, Stith AY, Nelson AR; Institute of Medicine (U.S.). Committee on Understanding and Eliminating Racial and Ethnic Disparities in Health Care. Unequal treatment: confronting racial and ethnic disparities in health care. Washington DC: National Academy Press, 2003.

33. Sequist TD, Adams A, Zhang F, et al. Effect of quality improvement on racial disparities in diabetes care. Arch Intern Med 2006;166:675-81.

34. Burgess DJ, Nelson DB, Gravely AA, et al. Racial differences in prescription of opioid analgesics for chronic noncancer pain in a national sample of veterans. J Pain 2014;15:447-55.

35. Trivedi AN, Grebla RC, Wright SM, et al. Despite improved quality of care in the Veterans Affairs health system, racial disparity persists for important clinical outcomes. Health Aff (Millwood) 2011;30:707-15.

36. Adams AS, Uratsu C, Dyer W, et al. Health system factors and antihypertensive adherence in a racially and ethnically diverse cohort of new users. AMA Intern Med 2013;173:54-61.

37. Schmittdiel JA, Karter AJ, Dyer W, et al. The comparative effectiveness of mail order pharmacy use vs. local pharmacy use on LDL-C control in new statin users. J Gen Intern Med 2011;26:1396-402.

38. Duru OK, Schmittdiel JA, Dyer WT, et al. Mail-order pharmacy use and adherence to diabetes-related medications. Am J Manag Care 2010;16:33-40.

39. Rittenhouse DR, Shortell SM, Fisher ES. Primary care and accountable care-two essential elements of delivery-system reform. N Engl J Med 2009;361:2301-3.

40. Rittenhouse DR, Thom DH, Schmittdiel JA. Developing a policy-relevant research agenda for the patient-centered medical home: a focus on outcomes. J Gen Intern Med 2010;25:593-600.

41. Marcotte L, Seidman J, Trudel K, et al. Achieving meaningful use of health information technology: a guide for physicians to the EHR incentive programs. Arch Intern Med 2012;172:731-6. 